\title{
JOURNAL OF AVIATION
}

\section{Küresel Seyrüsefer Uydu Sistemleri Kullanılamayan Alanlarda İnsansız Hava Aracinın Stabilizasyonunun Artırılması}

\author{
Fatma YILDIRIM DALKIRAN ${ }^{1 *}$ (D), Mustafa Samet GENÇA $\breve{G}^{2}$ iD \\ ${ }^{1}$ Erciyes Üniversitesi, Havacılık Elektrik ve Elektroniği Bölümü, Kayseri, Türkiye \\ ${ }^{2}$ Kapadokya Üniversitesi, Uçak Teknolojisi Programı, Nevșehir, Türkiye
}

\begin{abstract}
Özet
Günümüzde kullanılan insansız hava araçlarının (İHA) neredeyse tamamı, küresel seyrüsefer uydu sistemini (Global Navigation Setallite System, GNSS) kullanmaktadır. Bu sistem, hava aracına yüksek hassasiyetli konum, hız ve zaman bilgisi sağlamaktadır. Ancak GNSS kullanıldığında, yüksek yapıların arasında, engebeli arazilerin bazı bölgelerinde ve kapalı alanlarda veri akışında aksaklıklar meydana gelmektedir. Bu sistemin eksikliğinde, ataletsel ölçüm birimi (Inertial Measurement Unit, IMU) içerisinde bulunan jiroskop, ivmeölçer ve manyetometre verileri kullanılmaktadır. Kapalı ortamda uçuş yapılırken, harici bir seyrüsefer sistemi kullanılamadığı zaman, IMU' da sapmalar meydana gelmekte ve bu sapmalar, düzeltilememekte, uçuş boyunca da artarak devam etmektedir. Bu çalışmada, kapalı ortam uçuşlarında ortaya çıkan sapmaları azaltmak ve buna bağlı olarak uçuş stabilitesini artırmak için optik akış, kızılötesi ve ultrasonik sensörlerin birlikte kullanıldığ 1 bir İHA modeli sunulmuştur. Geliştirilen İHA' nın uçuş stabilitesini karşılaştırma açısından kapalı ortam uçuşu için iki farklı konfigürasyon kullanılmıştır. Arduino üzerinde geliştirilen algoritmalar sayesinde, IHHA’ nın kapalı alanda engellerden kaçınması sağlanmış ve hem IMU' daki sapmalar azaltılmış hem de uçuş stabilizasyonu artırılmıştır.
\end{abstract}

Anahtar Kelimeler: İHA, GPS’siz Uçuş, Sensör Füzyonu, Kapalı Alan, Stabilizasyon

\section{Increasing the Stabilization of Unmanned Aerial Vehicle in Global Navigation Satellite System Unavailable Areas}

\begin{abstract}
Nowadays nearly all of unmanned aerial vehicles (UAV) use Global Navigation Setallite System (GNSS). This system provides high-precision position, speed and time information to the aircraft. However, some problems can occour about data flow between high buildings, in some areas of rough terrain and indoor environment when GNSS is used. If this system is not available, the gyroscope, accelerometer and magnetometer data contained in the Inertial Measurement Unit (IMU) are used. Indoor flight, when an external navigation system cannot be used, deviations occur in the IMU. These deviations cannot be corrected and continue to increase throughout the flight. In this study, an UAV, in which optical flow, infrared and ultrasonic sensors are used together, has been presented to reduce the deviations that occur in indoor flights and increase flight stability accordingly. Two different configurations were used for indoor flight in terms of comparing the flight stability of the developed UAV. Thanks to the algorithms developed on Arduino, the UAV has been allowed to avoid obstacles in the closed area, and both the deviations in the IMU have been reduced and the flight stabilization has been increased.
\end{abstract}

Keywords: UAV, Flight without GPS, Sensor fusion, Indoor area, Stabilization

\author{
Corresponding Author/Sorumlu Yazar: Fatma YILDIRIM DALKIRAN fatmay@erciyes.edu.tr \\ Citation/Alıntı: Yıldırım Dalkıran F., Gençă̆ M.S. (2021). Küresel Seyrüsefer Uydu Sistemleri Kullanılamayan Alanlarda İnsansız \\ Hava Aracının Stabilizasyonunun Artırılması J. Aviat. 5 (1), 36-44. \\ ORCID: ${ }^{1}$ https://orcid.org/0000-0001-8663-241X ; ${ }_{-}^{2}$ https://orcid.org/0000-0002-3212-1814 \\ DOI: https://doi.org/10.30518/jav.932978 \\ Gelis/Received: 6 Mayıs 2021 Kabul/Accepted: 29 Haziran 2021 Yayınlanma/Published (Online): 30 Haziran 2021 \\ Copyright (C) 2021 Journal of Aviation https://javsci.com - http://dergipark.gov.tr/jav
}




\section{Giriş}

Drone olarak da adlandırılan insansız hava araçları (İHA) günümüzde hızlı bir şekilde yaygınlaşarak kendisine birçok kullanım alanı bulmuştur. Teknolojik gelişmelerle birlikte gelişen İHA'ların boyut ve kabiliyet olarak çok fazla çeşidi bulunmaktadır. Görüntü alma, yangın söndürme, lojistik, havadan haritalama, arama-kurtarma ve ilaçlama gibi birçok alanda insan hayatını tehlikeye atmadan ve insan kabiliyetlerinin sinırlı olduğu alanlarda kullanımı yaygınlaşmıştır [1-3].

Sabit ve döner kanatlı olmak üzere iki tip İHA vardır. İlk İHA' lar, radyo sinyalleri vasitasıyla yer istasyonundan bir operatör tarafindan kontrol edilmekte iken son zamanlarda tasarlanan İHA' lar, daha karmaşık sistemleri kullanarak, önceden programlanmış uçuş planlarına göre uçuş gerçekleştirebilmektedirler. İHA' ların otonom uçuşunda, uçuş kontrolcüsünde bulunan dahili atalet ölçüm birimi (Inertial Measurement Unit, IMU) kullanılmaktadır. IMU, başlangıç noktasından itibaren doğrusal hareketi ve açısal hareketi tespit etmek için üç ivmeölçere ve üç jiroskopa sahiptir ancak IMU ölçümlerinde kayma hataları oluşmakta ve bu hatalar, uçuş süresi uzadıkça artmaya devam etmektedir. Kayma hatası, çok küçük olsa bile zamanla büyük bir değere dönüşmektedir. IMU' nun bu kayma hatasını telafi etmek için GNSS konum bilgisi kullanılmaktadır [4-5].

Bazı küçük İHA' lar, navigasyon için tamamen GNSS' e güvenmektedirler. GNSS, arızalanmasına neden olabilecek kazara veya kasıtlı girişime karşı savunmasızdır. En iyi ortam koşullarında bile GNSS kesintileri, saniyeler hatta bazen dakikalarca sürebilmektedir [6]. GNSS kullanılamadığ 1 durumlarda, uçuş kontrolcüsünde yer alan dahili sensörler (IMU' da), özellikle kapalı alanda güvenli bir uçuş gerçekleştirmek için yeterli değildir [7]. Bu çalışmada, kapalı ortamlarda veya yüksek yapıların arasinda, GPS' in dolayisiyla GNSS' in kullanılamadığı durumlarda stabil bir uçuş gerçekleştirmek için geliştirilen 'İHA' dan bahsedilecektir. Uçuş stabilitesini sağlamak için geliştirilen bu İHA' da optik akış sensörü, ultrasonik sensör ve kızılötesi sensör kullanılmıştır.

İHA' ların dış ortamda gerçekleştirilen uçuşları ile ilgili literatürde çok sayıda çalışma olmasına rağmen kapalı ortamda gerçekleştirilen uçuşlarla ilgili yapılan çalışmaların sayısı çok azdır. $\mathrm{Bu}$ çalışmalardan birinde, insansız hava araçlarının kontrolü için doğru durum bilgisi gerekliliğine dikkat çekilmiştir. Bu amaçla kullanılan, uygun maliyetli mikro elektro mekanik sistemlerin (Micro Electro Mechanical System, MEMS) jiroskoplar1 ve ivmeölçerleri, fazla gürültülü çalışır iken güvenilir seyrüsefer bilgisi sağlamak için de GPS gibi ek bir komponente ihtiyaç duyuluyormuş. Yapılan bu çalışmada MEMS, GPS ve görüntü tabanlı sensör verileri füzyon edilmiş, Kalman filtresi ile de sapma miktarının azaltılması sağlanmıştır [8]. Bir başka çalışmada Shen et al., açık alanda GPS' siz mikro hava araçları (Micro Air Vehicle, MAV) için kullanılan ataletsel seyrüsefer sistemindeki (Inertial Navigation System, INS) sapmaların yüksek olması sebebiyle INS, optik akış sensörü ve manyetometre entegrasyonunu yapmışlar ve genişletilmiş Kalman filtresini kullanmışlardır. Yapılan çalışmada, MAV' 1n hızını ve konumunu tahmin etmek için INS ve optik akış bilgileri kullanılmıştır. MAV, durağan durumdayken veya sabit bir biçimde hareket ederken jiroskop, akselerometre ve manyetometre bilgileri, MAV durumunu tahmin etmek için dikkate alınmıştır. Jiroskop ise sadece MAV hızlanırken veya yavaşlarken, MAV durumunu tahmin etmek için kullanılmıştır. $\mathrm{Bu}$ çalışma sonucunda INS sapmalarının azalması sağlanmıştır [9]. Diğer bir çalışmada küçük hava araçlarında birer adet IMU ve tek gözlü kamera kullanılarak, ataletsel ölçümler ile İHA' nın yerdeki sabit bir nesneye olan uzaklık bilgisi dikkate alınarak otonom iniş, kapalı alan kullanımı ve otonom seyrüseferi gerçekleştirilmiştir [10]. Çalışmada, birçok araştırmanın konusu olan eşzamanlı lokalizasyon ve haritalama (Simultaneous Localization and Mapping, SLAM) ile genişletilmiş Kalman filtresi kullanmıştır. Kapalı alanda GPS kullanmadan otonom uçuş gerçekleştirilmiştir [10]. Lange ve arkadaşları ise bir kamera, sonar sensör ve optik akış sensörü ile GPS olmayan ortamda Kalman filtresi ile sapmaları azaltarak, otonom İHA' nın inişi ve pozisyon kontrolü için görsel tabanlı yaklaşım kullanmışlardır [7]. Bir başka çalışmada ise GPS' siz ortamda İHA üzerinde algılama ekipmanı olarak bir kamera ve bir IMU kullanılmıştır [11]. Yerde ise Optitrack hareket yakalama sistemi kullanılarak IHHA' nın 3 boyutlu 
pozisyonu çıkartılmıştır. Bu sistemle görsel bir hedefe ulaşılması veya bir hedefin takip edilmesi amaçlanmıştır. Ayrıca bu çalışmada kapalı döngü sisteminin kararlılığ 1 , Lyapunov analizi ile de doğrulanmıştır [11]. Stephen Carnduff tarafindan 2008 yılında yapılan çalışmada İHA' ların sistem tanımlaması ve genişletilmiş Kalman filtresi kullanılarak hava aracının durum değişkenlerinin tahmini yapılmıştır [12]. Bir diğer çalışma, dört rotorlu İHA' ların durum ve parametre kestirimi üzerine yapılmıştır [13]. Durum kestirimi için genişletilmiş Kalman filtresi ve IMU kullanılmıştır. Yapılan çalışmada hava aracının durum tahmininin, GPS sinyalinin zayıf olduğu ortamlarda hava aracının konum kestirimi için avantajları gösterilmiştir [13]. Yapılan bir başka çalışmada, görsel odometri (visual odometry, VO) ve SLAM gibi görsel tabanlı seyrüsefer kullanılarak GPS' den veri alınamadığı ortamlarda İHA' nın uçuşunu yönetmek için bir modüler çoklu sensör veri füzyon tekniği geliştirilmiştir [4]. Yalnızca araç üzerinde algılamaya dayalı, İHA' nın doğrusal hareket hızının tahmini için iki yöntemin önerildiği diğer bir çalışmada, tek bir yerleşik kamera tarafindan sağlanan küresel görüntü ölçümleri, IMU verileri ile ana verileri içerir [14]. İlk algoritma Lyapunov sentezi kullanılarak tasarlanmış, doğrusal olmayan bir gözlemciden oluşurken ikincisi, Kalman filtreleme tekniğine dayanmaktadır. Mevcut yaklaşımlardan farklı olarak hı, aracın 3D pozisyonunu tam olarak tahmin etmeye gerek kalmadan, doğrudan yerleşik görüntüden pozisyon tahmininden sağlanmıştır [14]. Driessen ve arkadaşları, düşük maliyetli sensörler kullanarak İHA' nın hız, yükseklik ve pozisyon tahmini için genişletilmiş Kalman filtresi tabanlı sensör füzyonu tasarlamışlardır [15].

\section{Materyal ve Metot}

$\mathrm{Bu}$ çalışmasında kullanılan İHA, dört rotorlu (Quadcopter) yapiya sahiptir. Quadcopterler, Quadrotor olarak da bilinmektedirler. Rotorlar, yukarı doğru bir itki üretir ve rotorlar, quadcopter, kütle merkezine eşit mesafede kare şeklinde yerleştirilir. Quadcopterin kontrolü, elektrik motorları tarafindan döndürülen rotorların açısal hızlarını ayarlayarak sağlanır [16]. Quadrotorlar, alt1 serbestlik derecesine sahipken kontrol edilebilir dört değişkeni bulunmaktadır. $\mathrm{Bu}$ durum, quadrotoru dinamik olarak kararsiz bir sistem yapmaktadır. Şekil 1' de dört rotorlu bir İHA modellemesi gösterilmektedir. Kontrol edilebilen değişkenlerin sayısı, quadcopterin havadaki konumunu ve durumunu etkileyen motorların sayısına eşittir. Quadcopter, eksenlerden biri etrafında dönüş hareketi yapmadan, yani eğimi olmadan ilerleme hareketi yapamamaktadır. Eğimi elde etmek için motorların torkunu eksenlerden birine göre değiştirmek gerekir. Bunu yapmak için, bir veya iki motor üzerindeki itişi artırmak veya azaltmak gerekir [17]
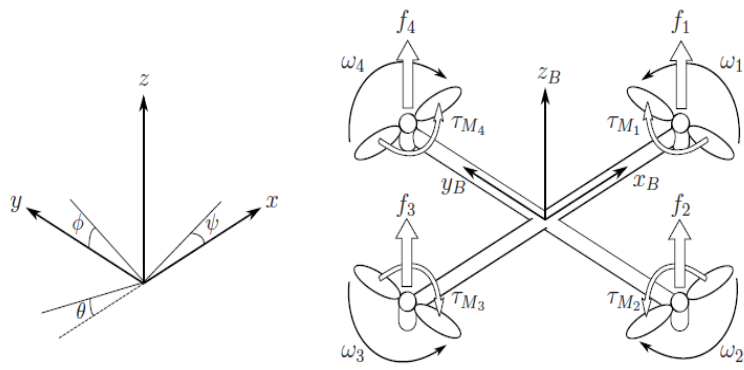

Şekil 1. Dört rotorlu bir İHA modellemesi [16]

Quadcopterin $\mathrm{x}, \mathrm{y}, \mathrm{z}$ eksenlerindeki lineer konumu, $\varepsilon$ ile Denklem 1' de tanımlanmıştır. Açısal konum, atalet referans çerçevesinde (inertial frame) üç Euler açısı, $\eta$ ile Denklem 1' de yer almaktadır. Şekil 1' de $\theta$ ile gösterilen yunuslama (pitch) açıs1, quadcopterin $y$ ekseni etrafındaki dönüşünü belirtmektedir. Şekilde yatış (roll) açısı olan $\phi, x$ ekseni etrafindaki dönüşü ifade ederken $\psi$ ile belirtilen sapma (yaw) açısı, $z$ ekseni etrafindaki dönüşü tanımlamakta kullanılır. Denklem 1' deki q vektörü, lineer ve açısal konum vektörlerini içermektedir [16].

$$
\varepsilon=\left[\begin{array}{l}
x \\
y \\
z
\end{array}\right], \quad \eta=\left[\begin{array}{l}
\phi \\
\theta \\
\psi
\end{array}\right], \quad q=\left[\begin{array}{l}
\varepsilon \\
\eta
\end{array}\right]
$$

Gövdenin merkezi, quadcopterin kütle merkezidir.

\subsection{Kapalı Alanda İHA Konfigürasyonları}

$\mathrm{Bu}$ çalışmada geliştirilen İHA üzerinde bulunan elektronik bileşenler ve bunların bağlantıları Şekil 2' de gösterilmiştir [18]. İHA üzerindeki bileşenler, bir quadcopterde de bulunması gereken 4 adet motor, 4 adet elektronik hız kontrolcüsü (Electronic Speed Controller, ESC), batarya, güç dağıtım kartı, uçuş kontrolcüsü, alıcı, güç modülü ve hava veri istasyonudur (HVİ). Bunların yanı sıra standart 
quadcopterden farklı olarak Arduino Mega, optik akış sensörü, PPM encoder, kızı̈ötesi sensör ve ultrasonik sensör gibi ek donanımlar kullanılmıştır. Geliştirilen İHA' nın karşılaştırmasını yapabilmek amacıyla iki farklı konfigürasyon kullanılmıştır.

Tablo 1' de gösterildiği gibi ilk konfigürasyonda hız ve konum bilgisi için IMU kullanılırken, ikinci konfigürasyonda IMU' ya ek olarak optik akış sensörü, kızılötesi sensör ve ultrasonik sensörler kullanılmıştır. Kullanılan sensörlerden optik akış sensörü, irtifa sabitlemesi ve konum bilgisi elde etmek için kullanılmıştır. Ultrasonik ve kızılötesi sensörler ise hem dar alanlarda duvarlara eşit mesafede ilerler iken stabiliteyi arttırmak için hem de karşılaşılan engellerden kaçınmak için kullanılmıştır. Birinci ve ikinci konfigürasyonda herhangi bir yapısal değişikliğe gidilmemiştir, bunun yerine birinci konfigürasyonda sensörler, yazılımsal olarak deaktif edilmiştir ve böylece karşılaştırma için eşit şartlar sağlanmıştır [18].

Şekil 2' de verilen bağlantı şemasında ana enerji kaynağ1 bataryadır. İHA üzerinde $14.8 \mathrm{~V}$ ideal gerilime sahip batarya kullanılmaktadır. Kaynaktan gelen gerilim, güç modülüne aktarılmıştır. Güç modülü, güç dağıtım kartına $14.8 \mathrm{~V}$ gönderirken, aynı zamanda gerilim düşümü yaparak, uçuş kontrolcüsünü de $5 \mathrm{~V}$ ile beslemektedir. Ayrıca güç

Tablo 1. İHA konfigürasyonlarında kullanılan sensörler

\begin{tabular}{ccc}
\hline Konfigürasyon & $\begin{array}{c}\text { Birinci } \\
\text { Konfigürasyon }\end{array}$ & $\begin{array}{c}\text { İkinci } \\
\text { Konfigürasyon }\end{array}$ \\
\hline GPS & X & X \\
\hline IMU & $\checkmark$ & $\checkmark$ \\
\hline $\begin{array}{c}\text { Optik Akış } \\
\text { Sensörü }\end{array}$ & X & $\checkmark$ \\
\hline $\begin{array}{c}\text { Kızı̈ötesi } \\
\text { Sensör }\end{array}$ & X & $\checkmark$ \\
\hline $\begin{array}{c}\text { Ultrasonik } \\
\text { Sensör }\end{array}$ & X & $\checkmark$ \\
\hline
\end{tabular}

modülü, bataryada kalan enerjinin yüzdelik olarak gösterilmesi için uçuş kontrolcüsüne bilgi de sağlamaktadır. Bu bilgi sayesinde uçuş esnasında bataryadaki güç tamamen bitmeden kullanıcı uyarılarak, IHA' nın güvenli bir şekilde inişi gerçekleştirilmiştir.

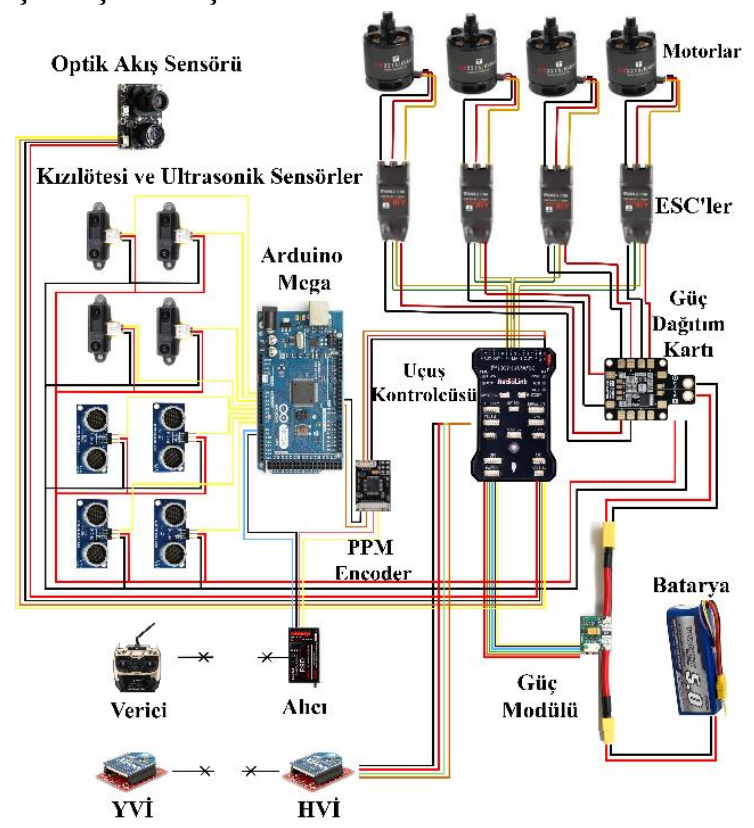

Şekil 2. Hava arac1 üzerinde bulunan bileşenlerin elektriksel bağlantı şeması

Şekil 3' te sensörlerden ve kumandadan gelen verilere göre, motorlara uygulanan sinyallerin, buna bağlı olarak İHA pozisyon kontrolünün bir șeması gösterilmektedir. Bu şemaya göre kumandanın 3. ve 4. sinyal kanalları pilot tarafından verilen sinyallere göre direkt olarak uçuş kontrolcüsüne gönderilmektedir. 3. ve 4. dördüncü kanallar sırasıyla gaz kolu ve yaw ekseninde dönüş sinyalleri; 1 . ve 2 . kanal sinyalleri ise sirasiyla yunuslama ve yatış eksenlerinde dönüş hareketi sağlamaktadır. Bunlar diğer kanallardan farklı olarak direkt olarak uçuş kontrolcüsüne gönderilememektedir. Eğer sensörler, bir engel ile

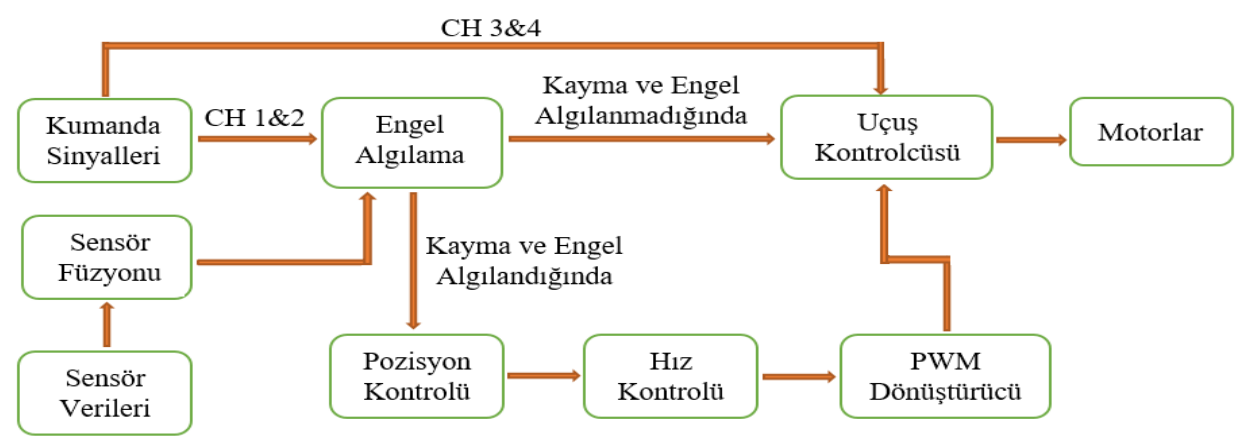

Şekil 3. Referans algılama ve engellerden kaçınma sistemi 
karşılaşırsa hava aracının kontrolünde kumandadan gelen sinyaller kullanılamamaktadır. Bunun yerine geliştirilen algoritma sayesinde hava aracının engellerden kaçınması ve referans noktalara olan mesafesinin korunması sağlanmaktadır.

IMU verileri ve sensör verileri kullanılarak hava aracının hızını ve konumunu, düzgün bir şekilde tahmin etmek için lineer Kalman filtresi kullanılmıştır. Elde edilen tahminler doğrultusunda PWM sinyaller üretilerek, uçuş kontrolcüsüne iletilmiştir. $\mathrm{Bu}$ sinyaller, yatış ve yunuslama eksenlerinde hareket etmek üzere sinyal üretmektedir. Ani manevralardan oluşabilecek kontrol kaybını önlemek için PWM çıkış sinyalleri sınırlandırılmıştır. Algılama alanı içerisinde herhangi bir engel veya referans noktası tespit edilemezse, İHA tamamen kullanıcı kontrolünde hareket etmektedir ve pilotun kumanda sinyalleri olduğu gibi uçuş kontrolcüsüne iletilmektir. Herhangi bir kumanda sinyali gönderilmediğinde bulunduğu konumda kendisini sabit bir şekilde tutmaktadır. Şekil 4' te İHA üzerinde bulunan sensörlerin algılama yönleri gösterilmiştir. Şekil 5' de de geliştirilen İHA' nın bir gösterimi yer almaktadır.

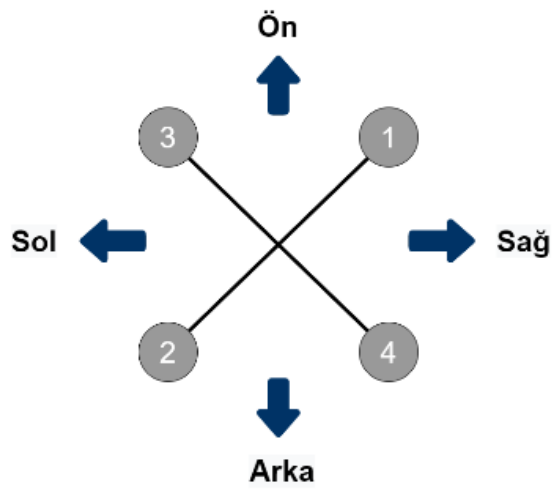

Şekil 4. Sensör algilama yönleri

\section{Bulgular ve Tartışmalar}

İHA uçuş konfigürasyonları 6 metre genişlik, 15 metre uzunluk ve 3,5 metre yükseklik ölçülerine sahip olan kapalı alanda gerçekleştirilmiştir. Kapalı alanda azami 3 metre yüksekliğe çıkılabilmiştir.

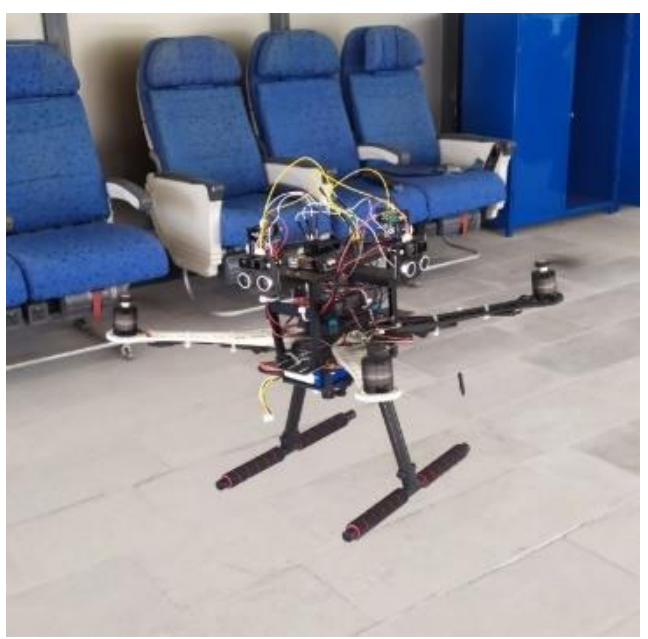

Şekil 5. Geliştirilen İHA uçuş görseli [18]

Birinci konfigürasyonda gerçekleştirilen uçuş boyunca yanal eksen üzerinde yaptığ 1 yunuslama açısının zamana göre değişimleri derece cinsinden Şekil 6(a)' da gösterilmiştir. Bu grafiğe göre, kumanda tarafindan hava aracina pitch manevra komutu gönderilmemesine rağmen yunuslama açısında istenmeyen sapmalar meydana geldiği gözlenmiştir. Bu sapmaların nedeni, IMU' nun tek başına kullanılmasıdır. IMU tek başına kullanıldığı zaman hatalar meydana gelmektedir. İHA' larda bu hatalar açık alanda GPS ile düzeltilirken, kapalı alanda GPS sinyallerinin zayıf olmasindan veya olmamasından dolayı düzeltme işlemi yapılamamaktadır. Yalnızca IMU verileri ile gerçekleştirilen uçuşlarda IMU' da oluşan hatalar devamlı meydana geldiği ve düzeltilemediği için, artarak da devam etmektedir. Bu sebepten dolay 1 elde edilen grafiklerden de görüldüğü üzere kapalı alanda yunuslama açısını sabit tutmak için IMU verileri yetersiz kalmaktadır. Şekil 6(b)' de ikinci konfigürasyon kullanılarak gerçekleştirilen uçuş boyunca yanal eksen üzerinde yaptığı yunuslama açısının zamana göre değişimleri derece cinsinden gösterilmiştir. Şekil 6(b)' de küçük periyotlar halinde yer alan aşırı sapmalar, İHA’ nın engellerle 


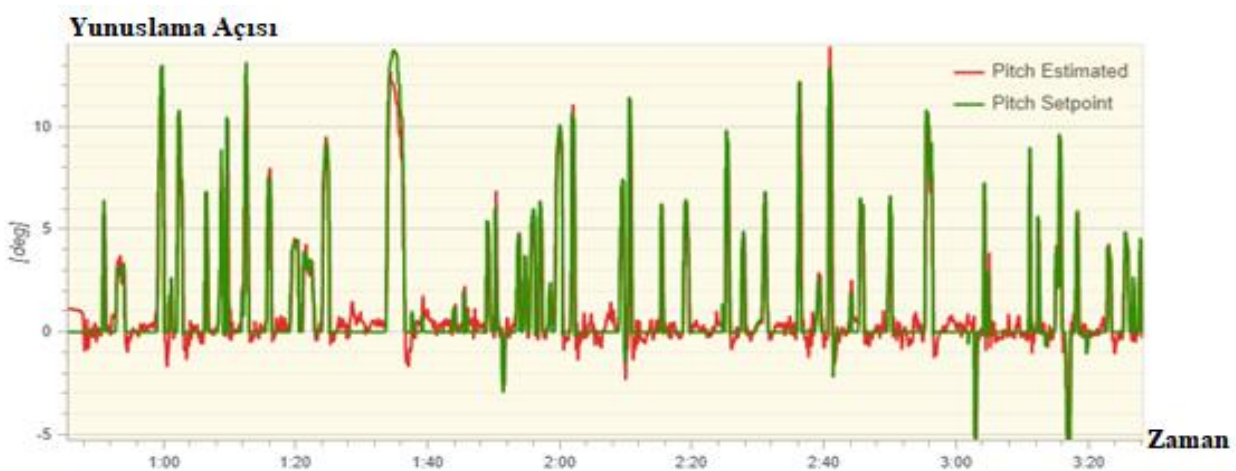

(a)

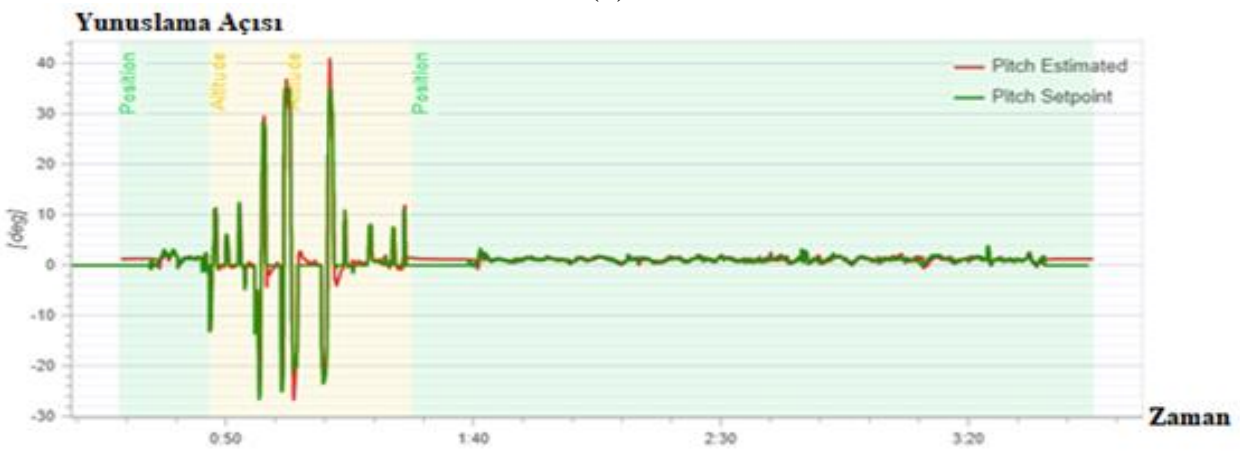

(b)

Şekil 6. Yunuslama açısı-zaman grafiği, (a) IMU verileri kullanılarak gerçekleştirilen uçuşta, (b) Sensör füzyonu kullanılarak gerçekleştirilen uçuşta

karşılaştığında engellerden kaçınmak için yaptığı ani manevralardan kaynaklanmaktadır. Herhangi bir engelle karşılaşılmadığında ani manevralar gerçekleşmemektedir ve buna bağlı olarak aşırı sapmalar meydana gelmememektedir.

İHA' nın birinci konfigürasyon uçuşu boyunca boylamsal eksen üzerinde yaptığı yatış açısının zamana göre değişimleri Şekil 7(a)' da gösterilmiştir. Grafikte de görüldüğü gibi yalnızca IMU verileri kullanılarak gerçekleştirilen uçuşta yatış açısında istenmeyen sapmalar meydana gelmiştir. $\mathrm{Bu}$ sapmalar sonucunda yatış açısını stabil tutmak için sadece IMU' dan alınan verilerin yetersiz olduğu gözlenmiştir. Şekil 7(b)' de ise ikinci konfigürasyon kullanılarak gerçekleştirilen uçuş boyunca boylamsal eksen üzerinde İHA'nın yaptığı yatış açısının zamana göre değişimi yer almaktadır. Grafikte kırmızı bölge aralığında gösterilen aşırı sapmalar, engellerle karşılaşılmasından kaynaklı meydana gelen sapmalardır. Herhangi bir engelle karşılaşılmadığ durumda hava aracı konumunu korumuştur. Birinci ve ikinci konfigürasyondaki yatış açısı eğrileri karşılaştırıldığı zaman, sensör füzyonu yapıldığında yatış açısı sapmalarında gözle görülür bir azalma olduğu gözlemlenmiştir. İlk uçuşta yapılan maksimum yatış açısı sapması, $-10^{\circ}$ ile $+12^{\circ}$ arasındayken sensör füzyonu yapıldığında bu sapma, $-4^{\circ}$ ile $+3^{\circ}$ arasında değişmektedir. $\mathrm{Bu}$ verilere göre ek sensörlerin kullanıldığı uçuşta, yatış açılarındaki maksimum sapmalar yaklaşık olarak \%68 oranında azalmıştır.

Şekil 8(a)' da birinci konfigürasyon kullanılarak gerçekleştirilen uçuş boyunca dikey eksen üzerinde yaptığı sapma açısının zamana göre değişimleri yer almaktadır. Grafik incelendiğinde sapma açısında meydana gelen istenmeyen sapmalar, yunuslama ve yatış açılarında olduğu kadar fazla olmamakla birlikte anlık olarak yüksek sapmalar meydana gelmiştir.

İkinci konfigürasyon kullanılarak gerçekleştirilen uçuş boyunca dikey eksen üzerinde yaptığı sapma açısının zamana göre değişimi ise Şekil 8(b)' de verilmiştir. Grafikler incelendiğinde birinci konfigürasyonda meydana gelen ani sapmaların, ikinci konfigürasyon kullanıldığında azaldığı gözlemlenmiştir. Birinci konfigürasyon ile gerçekleştirilen uçuşta maksimum $-5^{\circ}$ ile $+5^{\circ}$ arasında bir sapma tespit edilirken, diğer konfigürasyonda maksimum $-3^{\circ}$ ile $+4^{\circ}$ arasında bir sapma tespit edilmiştir. Böylece ek sensörler kullanıldığında sapma açısındaki maksimum sapmaların, yaklaşık \%30 azaldığı gözlemlenmiştir. 


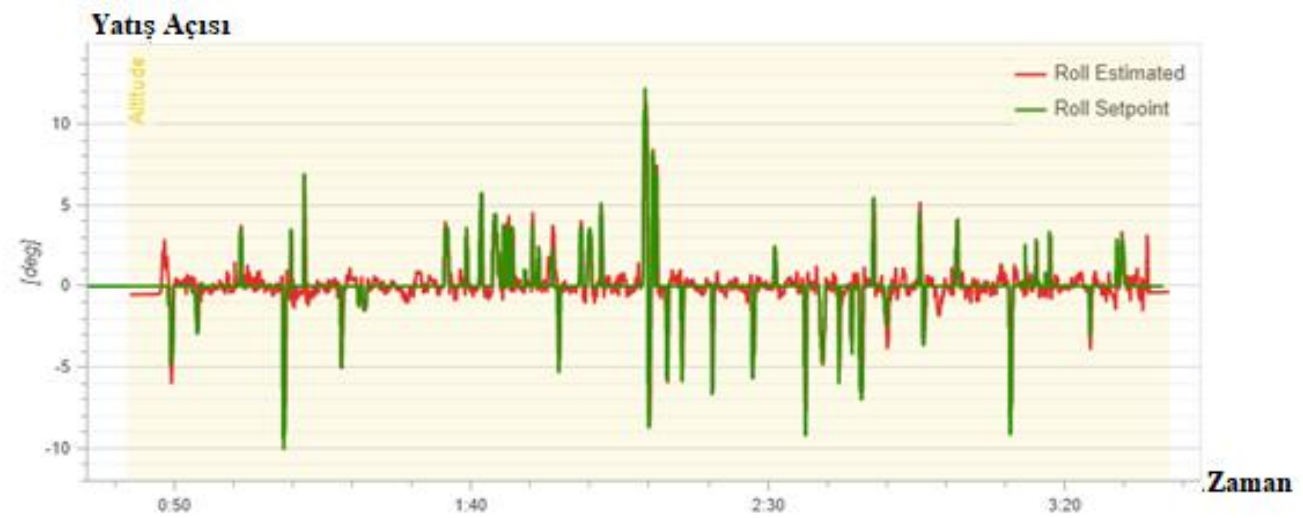

(a)

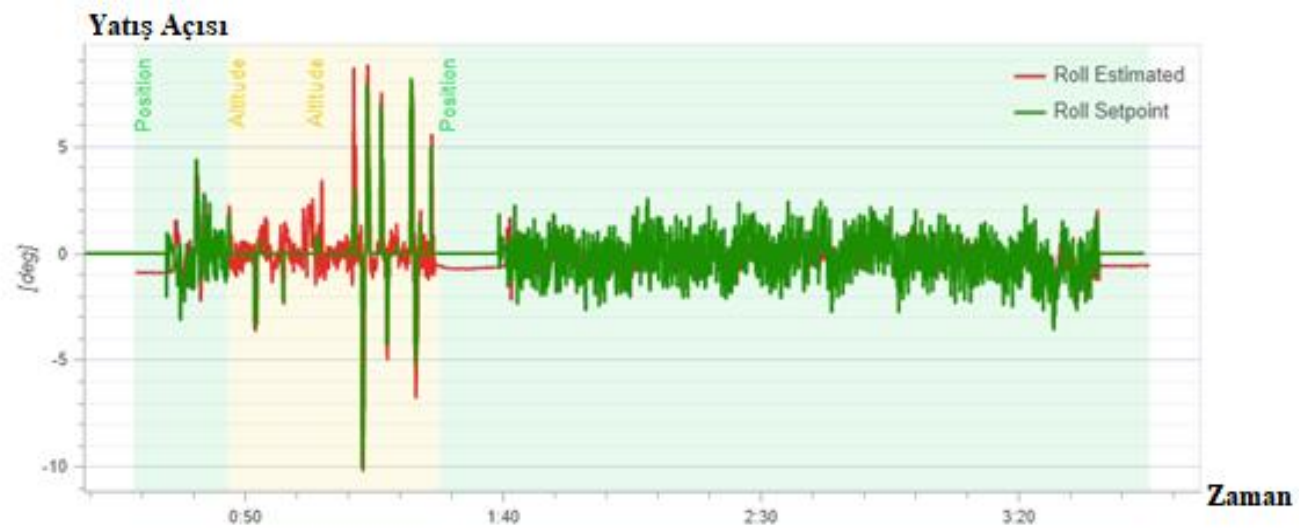

(b)

Şekil 7. Yatış açısı-zaman grafiği, (a) IMU verileri kullanılarak gerçekleştirilen uçuşta, (b) Sensör füzyonu kullanılarak gerçekleştirilen uçuşta

\section{Sonuçlar}

$\mathrm{Bu}$ çalışmada ilk olarak kapalı alanda sadece uçuş kontrolcüsü üzerindeki IMU verileri kullanılarak uçuş gerçekleştirilmiştir. Bu yapı birinci konfigürasyon olarak adlandırılmış ve bu uçuşun verileri alınarak incelenmiştir. Daha sonra İHA gövde yapısının alt kısmına optik akış sensörü, dört bir tarafina da birer adet kızılötesi sensör ve ultrasonik sensör yerleştirilerek sensör füzyonu yapılmıştır ve bu yap1 da ikinci konfigürasyon olarak tanımlanmıştır. Ayrıca elde edilen sensör verileri kullanılarak ani sapmaların önüne geçmek amacıyla Kalman filtresi uygulanmıştır. Bu uçuş sonucunda elde edilen uçuş verileri analiz edilmiş ve ilk uçuşla karşılaştırılarak grafikleri incelenmiştir. Çalışma kapsamında elde edilen grafikler incelendiğinde, kapalı ortamda yalnızca IMU kullanarak gerçekleştirilen uçuş ile ek sensörler kullanılarak gerçekleştirilen uçuş arasında, İHA' nın uçuş stabilitesi açısından farkl11ıklar gözlemlenmiştir. Ek sensörlerin kullanıldığı hava aracının uçuşlarının, hem daha stabil hem de daha az sapma oranına sahip olduğu görülmüştür.
Birinci konfigürasyona bakıldığında, yunuslama açısında maksimum $15^{\circ}$ gibi bir sapma meydana gelirken, ikinci konfigürasyonda bu, 4' 'ye kadar düşürülmüsşür. $\mathrm{Bu}$ verilere göre yunuslama açısındaki maksimum sapmalar, \%73 oranında azalmıştır. Ayrıca maksimum sapmalardaki azalmanın yanı sıra uçuş genelindeki yunuslama açısına bakıldığında, ikinci konfigürasyonda uçuşun daha stabil olduğu gözlemlenmiştir.

Başarılı gerçekleşen uçuşlar sonucunda elde edilen yatış grafiği incelendiğinde, yunuslama açısına benzer bir değiş̧im gözlemlenmiştir. Birinci konfigürasyonla gerçekleştirilen uçuş sonucu elde edilen yatış açısı grafiğindeki maksimum sapmalar, yaklaşık $22^{\circ}$ ' dir. Sensörlerin eklendiği, ikinci konfigürasyonla gerçekleştirilen uçuş sonucu oluşturulan grafikte ise yaklaşı $7^{\circ}$, lik bir sapma tespit edilmiştir. $\mathrm{Bu}$ bilgiler doğrultusunda, ikinci konfigürasyon kullanıldığında birinci konfigürasyona göre yatış açısındaki maksimum sapmalar \%68 oranında azalmıştır. Grafiğin geneline bakıldığında da yatış açısındaki sapmaların, ikinci konfigürasyon kullanıldığında azaldığı gözlemlenmiştir. 


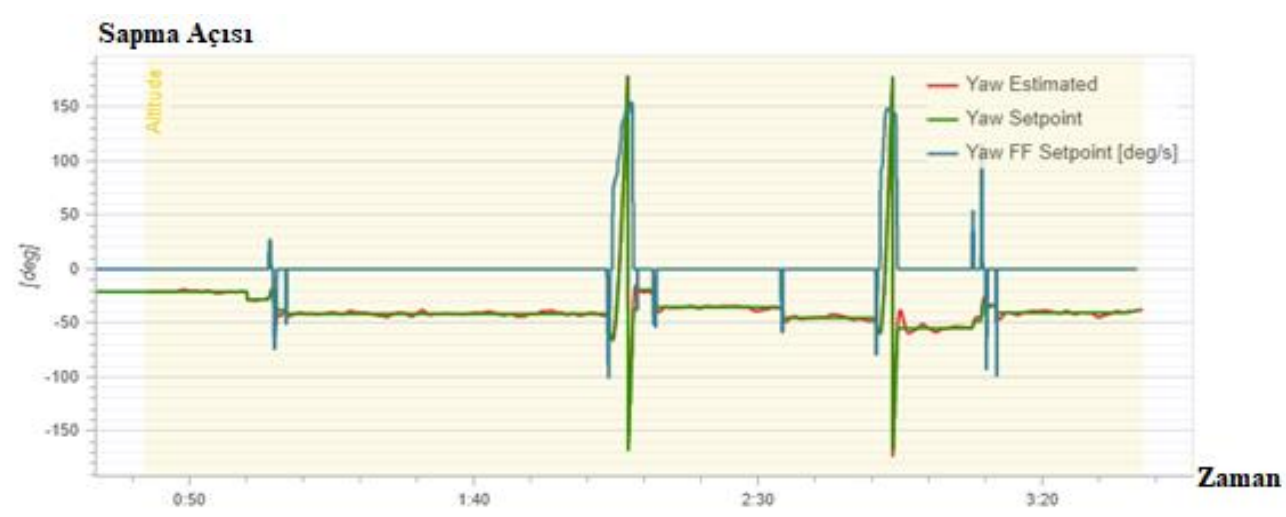

(a)

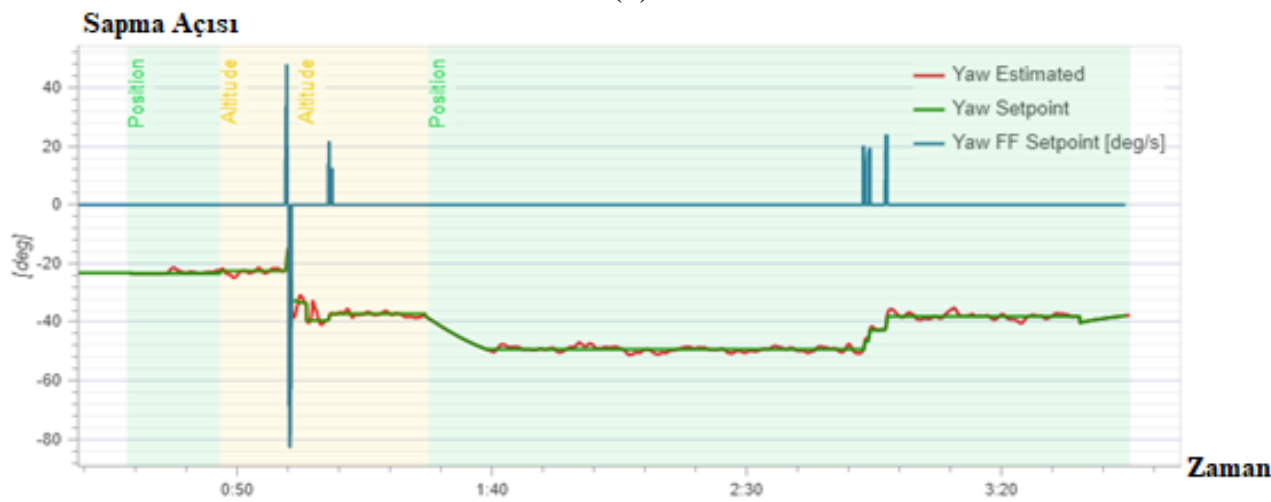

(b)

Şekil 8. Sapma açısı-zaman grafiği, (a) IMU verileri kullanılarak gerçekleştirilen uçuşta, (b) Sensör füzyonu kullanılarak gerçekleştirilen uçuşta

Kapalı ortamda İHA' nın uçuş stabilitesini inceleme açısından bakılan bir diğer parametre de sapma açısıdır. Sapma açısı, İHA’ nın dikey eksen üzerinde yaptığı dönüş açısını vermektedir. Karşılaştırmada yine iki ayrı konfigürasyon kullanılmıştır. Sapma açısında meydana gelen istenmeyen sapmalar, yunuslama ve yatış açılarına kıyasla daha düşük seviyededir. Sapma açısı grafikleri incelendiğinde, birinci konfigürasyon ve ikinci konfigürasyonda sırasıyla maksimum $10^{\circ}$, lik ve $7^{\circ}$ lik sapmalar meydana gelmiştir. Bu verilere göre sapma açısında meydana gelen maksimum sapma \%30 oranında azalmıştır.

$\mathrm{Bu}$ çalışma, ileride yapılacak olan, GPS' li uçuştan kapalı alana geçiş ve kapalı alanda otonom uçuş geliştirme çalışmalarına bir kaynak olacağı düşünülmektedir. Ayrıca geliştirilen bu İHA, geliştirilecek sürü İHA uygulamalarının 4 yönlü engellerden kaçınmasına da örnek olacaktır.

\section{Simgeler}

$\varepsilon$ : Hava aracı lineer konumu

$\eta$ : Hava aracı açısal konumu

q: Lineer ve açısal konum vektörleri

$\theta$ : Yunuslama açısı

$\phi:$ Yatış açısı $\psi$ : Sapma açıs1

\section{Teşekkür}

$\mathrm{Bu}$ çalışma Erciyes Üniversitesi Bilimsel Araştırma Projeleri Koordinasyon Birimi tarafindan FYL-2019-8951 nolu proje kapsamında desteklenmiştir.

\section{Etik Kurul Onayı}

Gerekli değil

\section{Kaynaklar}

[1] S. Akyürek, M. A. Yılmaz, M. Taşkıran, İnsansız hava araçları: Muharebe alanında ve terörle mücadelede devrimsel dönüşüm. Türkiye: Bilgesam Yayınları, İstanbul, 2012.

[2] M. Konar, "Redesign of morphing UAV's winglet using DS algorithm based ANFIS mode," Aircraft Engineering and Aerospace Technology, 1214-1222, 2019.

[3] M. Konar, E. T. Kekeç, "İnsansız Hava Araçlarının Uçuş Süresinin Termal Hava Akımları Kullanılarak Arttırımı," Avrupa Bilim ve Teknoloji Dergisi, (23), 394-400, 2021. 
[4] G. Balamurugan, J. Valarmathi, V.P.S. Naidu, "Survey on UAV Navigation in GPS Denied Environments," International Conference on Signal Processing, Communication, Power and Embedded System (SCOPES), Paralakhemundi, India, 2016, ss. 198-204.

[5] M. Konar, A. Turkmen, T. Oktay, "Improvement of the thrust-torque ratio of an unmanned helicopter by using the $\mathrm{ABC}$ algorithm," Aircraft Engineering and Aerospace Technology,1133-1139, 2020.

[6] G. Mao, S. Drake, B.D.O. Anderson, "Design of an Extended Kalman Filter for UAV Localization," IEEE Information, Decision and Control (IDC), Adelaide, Australia, 2007, ss. 224-229.

[7] S. Lange, N. Sunderhauf, P. Protzel, "A Vision Based Onboard Approach for Landing and Position Control of An Autonomous Multirotor UAV in GPS-Denied Environments," International Conference on Advanced Robotics, Munich, Germany, 2009, ss. 1-6.

[8] C. Schlaile, O. Meister, N. Frietsch, C. Keßler, J. Wendel, G.F. Trommer, "Using Natural Features for Vision Based Navigation of An Indoor-VTOL MAV," Aerospace Science and Technology, 13 (7), 349-357, 2009.

[9] C. Shen, Z. Bai, H. Cao, K. Xu, C. Wang, H. Zhang, D. Wang, J. Tang, J. Liu, "Optical Flow Sensor/INS/Magnetometer Integrated Navigation System for MAV in GPS-Denied Environment," Hindawi Publishing Corporation Journal of Sensors, 1-10, 2016.

[10] J. Langelaan, S. Rock, "Passive GPS-Free Navigation for Small UAVs," IEEE Aerospace Conference, Big Sky, USA, 2005, ss. 1-9.

[11] R. Mebarki, V. Lippiello, B. Siciliano, "Nonlinear Visual Control of Unmanned Aerial Vehicles in GPS-Denied Environments," The Institute of Electrical and Electronics Engineers, 31(4), 1004-1007, 2015.
[12] S. Carnduff, "System identification of unmanned aerial vehicles," Cranfield University, Doctorate Thesis, United Kingdom, 2008.

[13] S. C. Quebe, "Modeling, parameter estimation and navigation of indoor quadrotor robots," Brigham Young University, Master Thesis, United States of America, 2013.

[14] R. Mebarki, J. Cacace, V. Lippiello, "Velocity Estimation of an UAV Using Visual and IMU Data in a GPS-Denied Environment," IEEE International Symposium on Safety, Security, and Rescue Robotics (SSRR), Linkoping, Sweden, 2013, ss. 1-6.

[15] S. P. H. Driessen, N. H. J. Janssen, L. Wang, J. L Palmer, H. Nijmeijer, "Experimentally Validated Extended Kalman Filter for UAV State Estimation Using Low-Cost Sensors," 18th IFAC Symposium on System Identification (SYSID 2018), Stockholm, Sweden, 2018, ss. 43-48.

[16] T. Bresciani, "Modelling, identification and control of a quadrotor helicopter," Lund University, Master thesis, Sweden, 2008.

[17] Z. Benić, P. Piljek, D. Kotarski, "Mathematical Modelling of Unmanned Aerial Vehicles with Four Rotors," Interdisciplinary Description of Complex Systems: INDECS, 14(1), 88-100, 2016.

[18] M. S. Gençağ, "Kapalı ortamlarda insansız hava aracinin stabilizasyonunun iyileştirilmesi," Erciyes Üniversitesi, Fen Bilimleri Enstitüsü, Yüksek Lisans Tezi, Kayseri, Türkiye, 2020. 